\title{
Syphilis, gonorrhoea and genital chlamydial infection in a Somali village
}

\author{
S Osman Ismail, H Jama Ahmed, M Abdi Jama, K Omer, F Mohamed Omer, $M$ Brundin, \\ M-B Olofsson, L Grillner, S Bygdeman
}

\begin{abstract}
A total of 767 sera were collected from 187 men, 200 women and 380 children in a Somali village, Jambaluul. All sera were tested for syphilis serological markers by Venereal Diseases Research Laboratory (VDRL) and Treponema pallidum Haemagglutination Assay (TPHA). Sera positive for both or either of these tests were further analysed for the presence of specific IgM antibodies by Solid Phase Haemadsorption Assay (SPHA). A high and almost equal prevalence of TPHA positivity was found in men and women; $24 \%$ and $22.5 \%$, respectively, and IgM antibodies were found in $3 \%$ and $4 \%$, respectively. TPHA positivity significantly increased with age. Thus more than half of the villagers at the age of $\mathbf{4 5}$ years or more were TPHA positive. One percent of the children were TPHA positive. From all adults aged 15 years and above urogenital specimens were also taken for Chlamydia trachomatis antigen detection with an enzymeamplified immunoassay (IDEIA) and Neisseria gonorrhoeae culture. Chlamydial genital infection was found in $6 \%$ of the men and $18 \%$ of the women. All gonococcal cultures were negative.
\end{abstract}

In developing countries sexually transmitted bacterial infections such as syphilis and gonorrhoea are of major public health concern. ${ }^{12}$ Unlike the

Section of Bacteriology, Department of Pathology and Morphology

S Osman Ismail, $\mathrm{H}$ Jama Ahmed, $\mathrm{K}$ Omer

Department of Obstetrics and Gynecology

F Mohamed Omer

Department of Pediatrics, Banadir Maternal and Children's Hospital, Faculty of Medicine and Surgery, Somali National University, Mogadishu, Somalia

M Abdi Jama

Karolinska Institute, Department of Clinical Bacteriology, Huddinge Hospital

S Osman Ismail, H Jama Ahmed, M-B Olofsson, S Bygdeman

Karolinska Institute, Section of Virology, Department of Clinical Microbiology, Karolinska Hospital, Stockholm, Sweden

M Brundin, L Grillner findings in industrialised countries, the prevalence of gonorrhoea has increased rapidly over the last two decades in developing countries. ${ }^{2}$ In many African countries the seroprevalence of syphilis is still high and there is a considerable risk of congenital syphilis. ${ }^{34}$

Prevalence of clinical and subclinical infections due to Chlamydia trachomatis have been reported to be high both in men and women in many developing countries. ${ }^{2}$ Many studies have shown that secondary complications caused by $C$ trachomatis such as pelvic inflammatory diseases and secondary infertility in women and neonatal conjunctivitis in children are also common problems in these countries. ${ }^{5-7}$

In Somalia, the few studies regarding the prevalence of sexually transmitted diseases among different groups of Somali population have been so far confined to big urban centres such as Mogadishu, the capital city. In these studies a high prevalence of syphilis and genital chlamydial infection has been reported. ${ }^{89}$

The present study was undertaken to determine the prevalence of syphilis, gonorrhoea and genital chlamydial infection in a rural Somali population and to see if there is a difference in this regard between this population and urban dwellers.

\section{Materials and methods \\ GENERAL}

A typical Somali village was chosen. This village, Jambaluul, is situated along the river Shabelle $37 \mathrm{~km}$ to the southwest of the capital city Mogadishu. The inhabitants are mainly farmers. One or several houses with a small yard surrounded by a common fence constitute a compound or household where members of the same family or extended family live together. At the time of the study the total number of villagers was 977 and the total number of households 139. The mean number of persons per household was seven (range 1-33).

\section{STUDY POPULATION}

The study was conducted from August to September 1987. Thirty-four of the 977 inhabitants of the village were too young or seriously ill to be considered for the study. A total of $769(82 \%), 189$ men, 200 women 
Table 1 Total number of inhabitants in the Somali village of Jambaluul; those who were excluded, drop outs and those who participated in the study according to age group

\begin{tabular}{|c|c|c|c|c|c|}
\hline \multirow[b]{2}{*}{ Age group } & \multirow[b]{2}{*}{ Total } & \multicolumn{3}{|c|}{ Number of inhabitants } & \multirow{2}{*}{$\begin{array}{l}\text { o included inhabitants } \\
\text { out of eligible }\end{array}$} \\
\hline & & Excluded & Drop outs & Included & \\
\hline \multicolumn{6}{|l|}{ Males: } \\
\hline $0-7$ & 159 & 6 & 32 & 121 & 79 \\
\hline $8-15$ & 100 & 1 & 13 & 86 & 87 \\
\hline $16-23$ & 60 & 2 & 12 & 46 & 79 \\
\hline $24-31$ & 75 & 0 & 20 & 55 & 73 \\
\hline $32-39$ & 18 & 0 & 3 & 15 & 83 \\
\hline $40-47$ & 26 & 0 & 3 & 23 & 81 \\
\hline $48-55$ & 27 & 1 & 5 & 21 & 77 \\
\hline $56-63$ & 13 & 3 & 1 & 9 & 90 \\
\hline $64-71$ & 16 & 0 & 3 & 13 & 81 \\
\hline $72-79$ & 3 & 0 & 0 & 3 & 100 \\
\hline $80-87$ & 3 & 1 & 1 & 1 & 50 \\
\hline Total & 500 & 14 & 93 & 393 & 81 \\
\hline \multicolumn{6}{|l|}{ Females: } \\
\hline $0-7$ & 142 & 10 & 18 & 114 & 86 \\
\hline $8-15$ & 86 & 1 & 17 & 68 & 80 \\
\hline $16-23$ & 59 & 2 & 10 & 47 & 82 \\
\hline $24-31$ & 92 & 1 & 15 & 76 & 84 \\
\hline $32-39$ & 28 & 1 & 5 & 22 & 81 \\
\hline $40-47$ & 33 & 0 & 7 & 26 & 79 \\
\hline $48-55$ & 18 & 3 & 1 & 14 & 93 \\
\hline $56-63$ & 9 & 0 & 4 & 5 & 56 \\
\hline $64-71$ & 10 & 2 & 4 & 4 & 50 \\
\hline $72-79$ & - & - & - & - & - \\
\hline $80-87$ & - & - & - & - & - \\
\hline Total & 477 & 20 & 81 & 376 & 82 \\
\hline
\end{tabular}

and 380 children ( 204 boys and 176 girls) below 15 years of age, participated in the study (table 1 ).

The median age of the males was 14 years (range three months to 87 years) and of the females 17 years (range eight months to 67 years) (table 1).

Informed consent was obtained from the village authorities and from each adult participant. Consent was obtained from children through their parents. All participants were asked questions according to a standardised questionnaire for each group. Data collected included age, sex, occupation, marital status, polygamy, mean number of pregnancies, sex with prostitutes, as well as history of syphilis, genital discharge and genital ulcers. Several visits were made to Jambaluul to treat individuals found to have syphilis or genital chlamydial infection.

\section{COLLECTION OF SAMPLES}

Blood samples were drawn from each adult participant except two men and from older children by venipuncture and from younger children by fingerprick. After centrifugation sera were divided into 2-3 aliquots and stored at $-20^{\circ} \mathrm{C}$ until transported to Huddinge Hospital, Sweden, where serological markers for syphilis were tested. Sera from women were tested by the Venereal Disease Research Laboratory (VDRL) test in Mogadishu.

From all adults, 15 years of age and older, except six women who refused, urogenital specimens were taken for smear, $C$ trachomatis antigen detection and gonococcal culture. In women specimens were taken from both the urethra and the cervix except in virgins from whom specimens were taken only from the urethra.

Specimens for $C$ trachomatis antigen detection were taken by inserting a sterile ENT swab (ENT Swedish Hospital Supply, Mölndal, Sweden) into the anterior urethra and/or cervical canal and gently rotating it. The swabs were put into a special transport medium provided by the manufacturer and stored at $-20^{\circ} \mathrm{C}$ until analysed at Huddinge Hospital. Specimens from women for $C$ trachomatis antigen detection were analysed at the University Laboratory, Mogadishu, Somalia.

Specimens for gonococcal culture were taken with sterile cotton swabs which were directly inoculated onto Thayer-Martin medium with and without antibiotics. The plates were kept in a candle jar and transported to the University Laboratory the same day where they were further incubated at $37^{\circ} \mathrm{C}$ in the candle jar for 24-48 hours.

\section{SYPHILIS SEROLOGY}

A total of 767 serum samples were tested by VDRL and Treponema pallidum haemagglutination assay (TPHA). Sera which were found to be VDRL positive when tested in Mogadishu were retested in Stockholm and the result of this second test was assigned to the specimens. Samples reactive for VDRL and/or TPHA in 1:80 dilution or more were further tested for specific IgM antibodies by solid phase haemadsorption assay (SPHA). SPHA was 
performed as described by Schmidt ${ }^{10}$ and TPHA was performed according to the instructions of the manufacturer.

\section{CHLAMYDIA TRACHOMATIS ANTIGEN DETECTION}

Chlamydia trachomatis was detected using IDEIA (Boots-Celltech Diagnostics Ltd, UK) an enzymeamplified immunoassay. The test was performed as instructed by the manufacturer. Specimens were considered positive if the absorbance value was 0.05 absorbance units greater than the mean reading of three negative controls (cut off). All specimens with an absorbance value \pm 0.015 absorbance units from the cut off were retested in duplicate. However, when IDEIA was performed in Mogadishu, the spectrophotometer was out of order and the tests were read by naked eye. Only those tests with a clearcut colour change were considered to be positive.

\section{GONOCOCCAL CULTURE}

Oxidase positive, gram negative diplococci were identified as $N$ gonorrhoeae and classified into serogroups WI or WII/III with Phadebact Monoclonal GC Test (Pharmacia Diagnostics, Uppsala, Sweden).

\section{SMEAR}

Smears from urogenital swabs were gram stained and the presence of gram-negative intracellular diplococci was noted.

\section{Results \\ GENERAL \\ Out of the 189 men, $133(70 \%)$ were married and 25 of them were polygamous. One hundred and sixty nine $(85 \%)$ out of the 200 women were married and the mean number of pregnancies was five (range 0 18). The sexual debut for men was at 14 years of age (range 11-21) and $55(29 \%)$ men had a history of sex with prostitutes in Afgoye (district town $7 \mathrm{~km}$ away) and/or in Mogadishu. Such information was difficult to extract from women. As judged by the question- naires, $21(11 \%)$ of men had a history of genital ulcers, $60(32 \%)$ a history of genital discharge and 19 $(11 \%)$ out of 177 men claimed to have had syphilis in the past, whereas in women $50(25 \%)$ had a history of genital discharge and $60(30 \%)$ had a history of syphilis. Also $39(21 \%)$ of men and $11(6 \%)$ out of 198 women had taken antibiotics during the last year $(p<0.001)$. All adult persons had visited at least the nearest city, Afgoye, and most of them (187/189 men and 186/190 women) also Mogadishu. Ten of the men had been abroad.}

\section{SYPHILIS SERUM MARKERS}

The results of the VDRL, TPHA, and SPHA tests in the 187 men and 200 women are given in table 2 . A
Table 2 Results of VDRL Treponema pallidum Haemagglutination Assay (TPHA) and Solid Phase Haemadsorption Assay (SPHA) in 187 men and 200 women in the Somali village of Jambaluul

\begin{tabular}{llllll}
\hline & \multicolumn{2}{l}{ TPHA } & & & \\
\cline { 2 - 6 } & + & + & - & - & \\
Group & VDRL & & & & $\begin{array}{l}\text { Total } \\
\text { number }\end{array}$ \\
\cline { 2 - 6 } & + & - & + & - & 187 \\
Men & $8^{\star}$ & 36 & 5 & 138 & 1200 \\
\hline Women & $32 \dagger$ & 13 & 31 & 124 & 200 \\
\hline
\end{tabular}

^Five were SPHA positive. + Seven were SPHA positive.

total of $44(24 \%)$ of the men and $45(22.5 \%)$ of the women were TPHA positive. Out of the TPHA positive men and women five and seven, respectively, were found to have IgM antibodies as detected by SPHA.

TPHA positive men were more likely to have a history of syphilis than TPHA negative men; $23 \%$ $(9 / 39)$ and $7.5 \%(10 / 134)$, respectively $(p=0.01)$. This was also the case for women; 56\% (25/45) and $23^{\circ}{ }_{0}(35 / 154)$, respectively $(p<0.001)$. In addition, men with positive TPHA tests claimed to have had a history of genital ulcers more often than the TPHA negative men; $23 \%(10 / 44)$ and $7 \cdot 7 \%$ (11/143) respectively $(p=0.001)$. In women no correlation was found.

More women than men were VDRL positive: 63 $(32 \%)$ and $13(7 \%)$, respectively. Only five $(3 \%)$ out of 187 sera from men were VDRL positive but TPHA negative compared with 31 ( $16 \%)$ out of 200 sera from women $(p=0.001)$. There was no correlation between pregnancy and this serological pattern. Also eight ( $4 \%$ ) of the men compared with $32(16 \%)$ of the women were VDRL and TPHA positive $(p<0.001)$. On the other hand, men had a positive TPHA and a negative VDRL, $36(19 \%)$, more often than women, $13(6.5 \%)(p<0.001)$.

Forty (29\%) out of 139 men who were married, divorced or widowed were TPHA positive compared with four $(8 \%)$ of 48 single men $(p=0.01)$. Similarly, $40(24 \%)$ out of 168 married women were TPHA positive compared with none among the singles. However, all single women claimed to be virgins. Out of the 76 TPHA positive men and women who were married, 33 (16 men and 17 women) were married couples. In 15 other couples only the husband was TPHA positive and in seven others only the wife. Among these 15 TPHA positive men only one was VDRL positive and none was SPHA positive and among these seven women five were VDRL positive and one of these also SPHA positive. Three of the five SPHA positive men were married and their wives were all TPHA positive and one was also SPHA positive. The husbands of six of the SPHA positive women were investigated. Five of 
Table 3 Results of chlamydial antigen detection by IDEIA in urogenital specimens from 194 women in the Somali village of Jambaluul

\begin{tabular}{|c|c|c|c|c|}
\hline & \multicolumn{4}{|c|}{ Female cervical } \\
\hline & Positive & Negative & $N D$ & Total No. \\
\hline $\begin{array}{c}\text { Female ureth } \\
\text { Positive } \\
\text { Negative } \\
\text { ND } \\
\text { Total No. }\end{array}$ & $\begin{array}{r}11 \\
13 \\
0 \\
24\end{array}$ & $\begin{array}{r}9 \\
145 \\
2 \\
156\end{array}$ & $\begin{array}{r}1 \\
13 \\
0 \\
14\end{array}$ & $\begin{array}{r}21 \\
171 \\
2 \\
194\end{array}$ \\
\hline
\end{tabular}

these six men were TPHA positive one being SPHA positive as well.

Both in men and women a correlation was found between increasing age and TPHA positivity as shown in the figure $(p<0.001)$. From the age of 45 years $50^{\circ}{ }_{0}(27 / 54)$ of the men and $58^{\circ}{ }_{0}(21 / 36)$ of the women were TPHA positive. There was no correlation between sex with prostitutes and TPHA positivity.

Among the 380 children four $\left(1_{0}^{\circ}\right)$ were TPHA and VDRL positive, three of them also SPHA positive. The four children were three boys $3,6,12$ years old and one girl 13 years old, who came from different families. The 12 year old boy was SPHA negative. One boy (6 years old) had a TPHA and SPHA positive father and a TPHA positive mother. None of the parents or other household members of the three remaining children had syphilis markers.

\section{Chlamydia trachomatis}

Chlamydial antigen was detected in $11(6 \%)$ out of 189 men and $34(18 \%)$ of the women. Out of the 33 IDEIA positive women from whom both urethral and cervical specimens were taken, nine $(27 \%)$ were positive only in the urethra, $13(39 \%)$ only in the cervix and $11(33 \%)$ in both sites (table 3 ).

Nine $(82 \%)$ out of the 11 IDEIA positive men did not have urethral discharge and $27(79 \%)$ out of the 34 IDEIA positive women had also an asymptomatic infection. Four of the men and women with chlamydial infection were married couples (none of the men was polygamous). IDEIA positive men did not have a history of contact with prostitutes more often than IDEIA negative men: four (36\%) out of 11 against $51(29 \%)$ out of 175 (NS).

N GONORRHOEAE AND SMEAR

None of the villagers had a positive gonococcal culture and no smear was positive for intracellular gram-negative diplococci.

\section{Discussion}

Our results showed a high and almost equal prevalence of TPHA positivity in men and women; $\left(24^{\circ}{ }_{0}\right.$ and $22.5 \%$ ) respectively (table 2 ). These figures are comparable with results from Mogadishu and other African countries where a high prevalence of syphilis has been reported in different population groups. ${ }^{38}$ Noteworthy is that more than half of the villagers at the age of 45 years and older were TPHA positive.

In the present study women were more often VDRL positive than men. They were also more likely to have a positive VDRL test not confirmed by a positive TPHA indicating a non-specific reaction or syphilis in a very early stage. "This finding can not be explained by false VDRL positivity during pregnancy since there was no correlation between this serological pattern and pregnancy. A false positive reagin test may also be found in cases of acute or chronic infections such as malaria." However, women should not be more likely to have such infections than men. In addition, significantly more women than men were both VDRL and TPHA positive $\left(16^{\circ}{ }_{0}\right.$ and $4^{\circ}{ }_{0}$, respectively) indicating untreated, active syphilis. TPHA positive sera lacking VDRL reactivity can be considered as an indication of successfully treated syphilis. In the present study men were more likely to have this kind of serological profile than women. These findings suggest that men might be more prone to seek medical treatment than women. This is in agreement with the finding that $21^{\circ}$ o of the men had used antibiotics during the last year as compared to $6^{\circ}{ }_{0}$ of the women $(\mathrm{p}<0.001)$.

A strong correlation was found between TPHA positivity and age in both men and women (fig). These results agree with other findings in which TPHA positivity has been shown to increase with age in a population with a high prevalence of syphilis. ${ }^{12}$ Similarly, Jama et $a l^{8}$ have found that TPHA positivity increased with age in a group of prostitutes with a high prevalence of syphilis in Mogadishu.

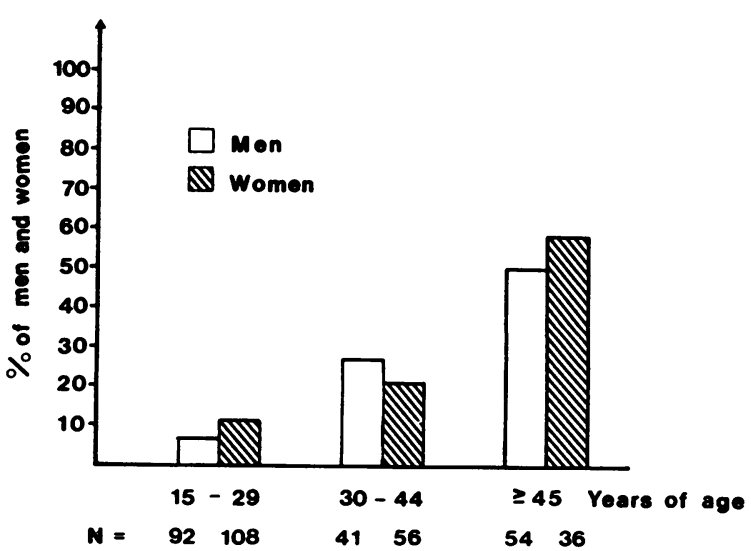

Fig Prevalence of serum antibodies to Treponema pallidum as judged by the Treponema pallidum haemagglutination assay (TPHA) in 187 men and 200 women in the Somali village of Jambaluul correlated to age. 
More than one third (33/89) of the TPHA positive men or women had a TPHA positive wife or husband, respectively, and seven out of eight SPHA positive adults had a husband/wife included in the study who was TPHA positive. In the couples where only one partner was TPHA positive more women than men were also VDRL positive indicating an active infection. This might indicate either that the transmission of syphilis from women to men is less efficient than vice versa or that the VDRL positivity in these women was due to unspecific reactions. Thus, intraconjugal transmission of syphilis between husband and wife seems to play an important role in the spread of syphilis among this population, where syphilis is endemic. Also, no correlation was found between TPHA positivity and sex with prostitutes.

The fact that TPHA positive persons significantly more often had a history of syphilis than those who were TPHA negative indicates a widespread public consciousness about syphilis among the villagers. On the other hand there were also TPHA negative persons who claimed to have a history of syphilis.

Although we could not find any syphilis IgM antibodies in children between three months and three years of age the risk of congenital syphilis can not be ruled out in such a population with a high prevalence of syphilis and inadequate medical facilities. The four TPHA and VDRL positive children were between three and 13 years of age. For the 13 year old girl, acquisition through sexual contact can not be excluded. Since the sexual debut for men in Jambaluul was at 11-21 years of age the 12 year old boy might also have acquired his syphilis sexually. The six year old boy, both parents of whom had syphilis serum markers, may have a congenital syphilis. Muller and Oelrich ${ }^{13}$ have reported the persistence of syphilis IgM antibodies for years. We cannot, however, explain the mode of acquisition of syphilis for the three year old boy who was positive for all three syphilis markers and the parents and other household members of whom were negative. Since no case of yaws has recently been reported from Somalia ${ }^{14}$ this disease does not seem to explain these serological findings.

The prevalence of genital chlamydial infection in women $(18 \%)$ was higher than that found among the men $(6 \%)$. The high prevalence of chlamydial infection in women is comparable with that reported by Jama et al for a group of pregnant women in Mogadishu (19\%). ${ }^{9}$ Several studies have been performed to assess the diagnostic prestanda of IDEIA. ${ }^{15-18}$ The results have varied considerably. Thus, the sensitivity has been reported to be between $56 \%$ and $99 \%$ while the specificity mostly has been in the order of $98-100 \%$. The true prevalence of chlamydial genital infection among the villagers might, therefore, be higher than reported specially among the women since the IDEIA tests for this group were read by naked eye. The storage at $-20^{\circ} \mathrm{C}$ of the specimens should not have influenced the test results since it has been shown that such storage for up to eight months did not considerably influence the test results. ${ }^{19}$

It is important to take specimens from both the urethra and the cervix. If only cervical specimens had been taken about one third of the cases of chlamydial infection would have been missed. In Somalia virtually all women are circumcised. In circumcised women cervical specimens may be difficult to obtain. In the present study $38^{\circ}$ of the cases of chlamydial infection in women would have been missed without cervical specimens.

Among the IDEIA positive men as many as $82 \%$ had an asymptomatic infection like $79 \%$. of the women. Identification and treatment of these asymptomatic carriers and their partners would be of the utmost importance in controlling chlamydial infections and their complications.

Although $\mathrm{Ngonorrhoeae}$ was not isolated from any of the adult villagers from whom specimens were available, we isolated $N$ gonorrhoeae from the urethra of one woman who was visiting but not residing in the village. Both the culture and the smear were positive and the strain belonged to serogroup WI (not betalactamase producing). This shows that the negative gonococcal cultures in the study were not due to unsuccessful culture procedures.

As shown in the present study, both the prevalence of syphilis as measured by TPHA positivity and that of chlamydial genital infection were at least as high in the village as in Mogadishu. Introduction of preventive measures such as routine screening of at least pregnant women and treatment programmes are badly needed in the rural areas in Somalia.

This study was supported by the Swedish Agency for Research Cooperation with Developing Countries (SAREC) and the Somali Academy of Science and Arts (SOMAC). The participation of Said Osman Ismail has been made possible thanks to a fellowship from the Swedish Institute. We thank the villagers in Jambaluul, in particular the members of the Village Committee and the Primary and Community Health workers, for their valuable support and collaboration. We also thank Abbott Scandinavia AB, Astra Alab AB, ERCO Läkemedel AB, AB Ferrosan, Hässle $A B$, Janssen Pharma $A B$, Kabi Vitrum Sverige AB, AB Leo Rhodia, Lever AB, AB H. Lundbeck \& Co, Merck AB, Pfizer AB, Pharmacia AB, Roche Producter AB, and Upjohn AB, Sweden, for generous support.

Address for reprints: Dr Said Osman Ismail, c/o Ass. prof. Solgun Bygdeman, Department of Clinical Bacteriology, Huddinge University Hospital, S-141 86 Huddinge, Sweden 
1 Osoba AO. Sexually transmitted diseases in tropical Africa. A review of the present situation. $\mathrm{Br} J$ Venereal Dis 1981;57: 89-94.

2 World Health Organization Expert Committee on Venereal Diseases and Treponematoses. Tech Rep Ser 1986:No.736.

3 Ratnam AV, Din SN, Hira SK, et al. Syphilis in pregnant women in Zambia. Br J Venereal Dis 1982;58:173-9.

4 Friedman PS, Wright DJM. Observations on syphilis in Addis Ababa: prevalence and natural history. Br J Venereal Dis 1977;53:276-80.

5 Mabey DCW, Ogbaselassie G, Robantson JN, Heckels JE, Ward ME. Tubal infertility in The Gambia: chlamydial and gonococcal serology in women with tubal occlusion compared with pregnant controls. Bulletin of WHO 1985;63: 1107-13.

6 Cates W, Farley TMM, Rowe PJ. Worldwide pattern of infertility: is Africa different? Lancet 1985;ii:596-8.

7 Fransén L, Nsanze H, Klauss V, et al. Ophthalmia neonatorum in Nairobi, Kenya: the roles of Neisseria gonorrhoeae and Chlamydia trachomatis. J Infect Dis 1986;153:862-9.

$8 \mathrm{Jama} \mathrm{H}$, Hederstedt B, et al. Syphilis in women of reproductive age in Mogadishu, Somalia: serological survey. Genitourin Med 1987;63:326-8.

9 Jama Ahmed H. Infections associated with sexual transmission in Somalia. Studies with special attention to women of reproductive age. Masters Thesis, 1986, Stockholm, Sweden.

10 Schmidt BL. Solid-phase hemadsorption: a method for rapid detection of Treponema pallidum-specific IgM. Sex Transm Dis 1980;7:53-8.

11 Bradford LL, Larsen SA. Serologic tests for syphilis. In:
Lennette EH, Balows A, Hausler WJ Jr, Shadomy HJ, eds. Manual of Clinical Microbiology, 4th ed. Washington, DC: ASM. 1985:910-20.

12 Ursi JP, van Dyck E, van Houtte C, et al. Syphilis in Swaziland. A serological survey. Br J Venereal Dis 1981;57:95-9.

13 Muller F, Oelrich S. Identification of low molecular weight IgM antibody with Treponema pallidum specificity in sera of patients with chronic syphilis. Klin Wochenschr 1979;57: 667-71.

14 World Health Organization. Endemic treponematosis. Weekly Epidemiological Record 1986;26:198-201.

15 Caul EO, Paul ID. Monoclonal antibody based ELISA for detecting Chlamydia trachomatis. Lancet 1985;i:279.

16 Pugh SF, Slack RCB, Caul EO, Paul ID, Appleton PN, Gatley S. Enzyme amplified immunoassay: a novel technique applied to direct detection of Chlamydia trachomatis in clinical specimens. J Clin Pathol 1985;38:1139-41.

17 Grillner L, Beckman S, Hammar H. Comparison of two immunoassays and an immunofluorescence test for detection of Chlamydia trachomatis. Eur J Clin Microbiol 1986;5:559-62.

18 Hong Tjiam K, van Heijst BYM, van Zuuren A, et al. Evaluation of an enzyme immunoassay for the diagnosis of chlamydia infections in urogenital specimens. J Clin Microbiol 1986; 23:752-4.

19 Bygdeman S, Teichert C, Ahlin A, Lidbrink P, Ahmed HJ. Influence of storing urogenital specimens at $-20^{\circ} \mathrm{C}$ before testing by enzyme amplified immunoassay (IDEIA) to detect Chlamydia trachomatis antigen. Genitourin Med 1989;65:92-5.

Accepted 27 November 1989 